\title{
On Epidemics, Epidemiology, and Global Storytelling
}

\author{
CARLOS ROJAS
}

Reviews of

Contagious Divides: Epidemics and Race in San Francisco's Chinatown by Nayan Shah, University of California Press, 2002

SARS in China: Prelude to Pandemic? edited by Arthur Kleinman and James Watson, Stanford University Press, 2016

Contagious: Cultures, Carriers, and the Outbreak Narrative by Priscilla Wald, Duke University Press, 2008

The Great Manchurian Plague of 1910-1911: The Geopolitics of an Epidemic by William Summers, Yale University Press, 2012

Infectious Change: Reinventing Chinese Public Health after an Epidemic by Katherine Mason, Stanford University Press, 2016

Epidemics and Society: From the Black Death to the Present by Frank M. Snowden, Yale University Press, 2020

Near the end of his 2019/2020 book Epidemics and Society: From the Black Death to the Present, ${ }^{1}$ Frank Snowden quotes from a 1998 report by the US Department of Defense that concluded, "Historians in the next millennium may find that the 20th century's greatest fallacy was the belief that infectious diseases were nearing elimination. The resultant complacency has actually increased the threat."2 Surveying a variety of different

1. As noted below, Snowden's book was first published in late 2019 but was republished in paperback, with a new preface, in early 2020. See Frank M. Snowden, Epidemics and Society: From the Black Death to the Present (New Haven, CT: Yale University Press, 2019).

2. Snowden, Epidemics and Society, 465. 
infectious diseases that have plagued humanity from antiquity to the present, Snowden argues that although these diseases have had a devastating impact on human society, the threat they posed has also catalyzed a series of advances in public health and biomedical knowledge. In particular, he points to the "sanitary revolution" and the "germ revolution" that began in the mid- and late-nineteenth-century periods, respectivelysuggesting that it was the success of these two overlapping revolutions that led to the mid-twentieth-century optimism that it might be possible, as US Surgeon General William Stewart allegedly put it in 1969, to "close the book on infectious diseases." ${ }^{3}$ At the same time, however, Snowden also argues that, in many instances, these same medical advances fostered a culture of complacency that made it easier for new infectious diseases to spread.

Indeed, despite the mid-twentieth-century optimism that it might soon be possible to make epidemics things of the past, smallpox remains the only major infectious disease to have been successfully eradicated, and new pathogens continue to emerge at a relentless pace. Snowden notes that since 1970, more than forty new diseases ("emerging infectious diseases") have been identified, and in the five-year span from 2002 to 2007 alone, there were "a record of eleven hundred worldwide epidemic 'events." "'4 Moreover, given the growing number of people who live in densely populated urban areas around the world and who travel routinely from place to place, once new infectious diseases emerge or reemerge, there is an ever-present possibility that they will reach epidemic proportions.

In fact, just two months after the initial October 2019 hardcover publication of Snowden's book-which is based on a lecture course he had been teaching annually at Yale over a seven-year period-the first documented cases of the new viral influenza that would come to be known as Covid-19 were reported in Wuhan, China. Snowden's book was then rereleased in a paperback edition in May 2020, with a new preface addressing the study's implications for this new disease. ${ }^{5}$ In this new preface, Snowden argues that the global response to Covid-19 up to that point had been symptomatic of a more general pattern in public health policy since World War II wherein "each [new] microbial challenge has been followed by a period of frenetic activity at every level, nationally and internationally, but has concluded with a lapse into forgetfulness." It is precisely this "forgetfulness," he argues, that facilitates the subsequent emergence and spread of new infectious diseases.

3. Snowden, 452-53; although, as Belinda Kong details in a recent article, this quote attributed to Stewart is actually apocryphal. The fact that it has been quoted in a wide array of authoritative sources suggests the degree to which it captured an attitude that was prevalent in the latter half of the twentieth century. See Belinda Kong, "Pandemic as Method," PRISM: Theory and Modern Chinese Literature 16, no. 2 (October 2019): 368-89.

4. Snowden, Epidemics and Society, 465.

5. See Snowden, Epidemics and Society: From the Black Death to the Present (New Haven: Yale University Press, 2020).

6. Snowden, Epidemics and Society, x-xi. 
Even as Snowden argues that responses to new infectious diseases have been hobbled by a pattern of generalized amnesia, however, he also makes the inverse argument - that, historically, health experts have often been too reliant on the memory of earlier responses to infectious outbreaks, and as a result they frequently fail to tailor their health policies to address the specificities of new threats. In particular, he contends that, despite the significant advances in public health and medical knowledge since the mid-nineteenth century, modern responses to new infectious diseases are influenced by strategies that were initially developed to combat the plague in the medieval era, and particularly policies of compulsory segregation and quarantine. Snowden notes that these measures,

however successfully deployed against bubonic plague, proved to be useless or even counterproductive when used against infections with profoundly different modes of transmission. In this manner the plague regulations established a style of public health that remained a permanent temptation, partly because they were thought to have worked in the past and because, in a time of uncertainty and fear, they provided the reassuring sense of being able to do something. In addition, they conferred upon authorities the legitimating appearance of acting resolutely, knowledgeably, and in accord with precedent. ${ }^{7}$

One of the key themes that runs through Snowden's book, accordingly, involves a persistent mismatch between the threat posed by infectious diseases, on one hand, and the policies that have been used to address that threat, on the other.

As indicated by his subtitle, From the Black Death to the Present, Snowden's study traces a trajectory from the fourteenth-century Black Death pandemic to twenty-first-century epidemics like SARS and Ebola. Black Death was, of course, the most notorious outbreak of a deadly disease whose English name, the plague, has become virtually synonymous with mass pestilence. It is now understood that the plague is caused by the bacterium Yersinia pestis and takes three distinct forms-bubonic, septicemic, and pneumonic plague-depending on which organ systems the bacterium infects. There have also been at least three major plague pandemics in human history. The first, known as the Justinianic plague, first erupted in the sixth century in the Nile Delta and then ravaged the Byzantine Empire and surrounding regions in successive waves for the next two centuries. The second, the Black Death, was transmitted in the fourteenth century from Central Asia to Europe, where a series of lethal outbreaks devastated the continent until the early eighteenth century. Finally, the so-called Third Pandemic broke out in southwestern China in the mid-nineteenth century, and after reaching Hong Kong in

7. Snowden, 81. 
1894 it was quickly transmitted around the world primarily along British trade routes, resulting in a pandemic that was not officially suppressed until 1960.

What makes the Third Pandemic particularly interesting is that it is not only synonymous with a devastating and deadly infectious disease, it was also the first pandemic to emerge in the era of modern biomedicine. That is to say, while humanity had few tools other than quarantine to confront the first two plague pandemics, the Third Pandemic coincided with the late-nineteenth-century "germ revolution," and within months of the disease's arrival in Hong Kong in 1894 the French microbiologist Alexandre Yersin had already succeeded in isolating the relevant pathogen. ${ }^{8}$ Four years later, the French physician Paul-Louis Simond theorized that rats and fleas might play a key role in transmitting the disease to humans, and this hypothesis was effectively confirmed a decade later by a series of studies conducted by the Indian Plague Commission between 1908 and 1909.

Despite this new biomedical knowledge regarding the etiology of the disease, however, there remained considerable variation in how different communities responded to plague outbreaks. For instance, in the fall of 1910, shortly after confirmation of the plague's primary vector of transmission, one of the worst outbreaks of the Third Pandemic began to unfold in Manchuria, in northeastern China, and the resulting crisis offered a test case in the ways in which public health policy was conditioned by underlying cultural tendencies and sociopolitical orientations. As William Summers notes in his study The Great Manchurian Plague of 1910-1911: The Geopolitics of an Epidemic, the Manchurian outbreak (primarily taking the form of pneumonic plague, which infects the lungs and can be spread from person to person via airborne droplets) ultimately killed as many as sixty thousand people in the region. This created a humanitarian catastrophe that rivaled or exceeded that of the mid-seventeenth century Great Plague of London, which Daniel Defoe famously chronicled in a quasi-fictionalized manner in his A Journal of the Plague Year. ${ }^{9}$ Moreover, what makes the Manchurian outbreak particularly instructive is that not only did it emerge at a crucial juncture in medical understandings of the disease, it also unfolded in a multiethnic and multinational territory positioned at the interstices of three sociopolitical regimes, each with very different approaches to public health.

In particular, in the early twentieth century, Manchuria-a region that is regarded as the ancestral homeland of the Manchus, the ethnic group of the Qing Dynasty, which ruled China from 1644 to 1911 — was the site of a complex geopolitical power struggle

8. The Japanese microbiologist Shibasaburo Kitasato is often credited with having isolated the bacterium virtually simultaneously yet independently of Yersin. However, as William Summers notes, what Kitasato isolated was in fact an unrelated contaminant. See William C. Summers, The Great Manchurian Plague of 1910-1911: The Geopolitics of an Epidemic Disease (New Have, CT: Yale University Press, 2012), 155.

9. Summers, The Great Manchurian Plague of 1910-1911, 198. 
between China, Russia, and Japan. At the time, Russia controlled parts of Manchuria resulting from an 1896 secret accord between Russia and China, even as Japan, building on concessions it obtained following its victory in the 1904-1905 Russo-Japanese War, was beginning to stake its own imperial claims in the region. As a result, when the plague struck Manchuria in 1910, the region was still nominally under the control of China, though the strategically important Chinese Eastern Railroad (running across the northern part of the region and southward to the city of Changchun) was controlled by Russia and the South Manchuria Railroad (running south from Changchun to the city of Dairen) was controlled by Japan.

Just as the Third Pandemic spread around the world primarily along maritime trade routes, once it reached Manchuria, it then moved southward primarily along the trajectory of the railroad, and Summers examines how different cities along the railroad responded to the health crisis. The first city in Manchuria affected was Harbin, in the north. At the time, Harbin was a new town under Russian control, and it quickly implemented a system of strictly enforced quarantines that ultimately contained the epidemic but generated considerable internal tension and discord. Meanwhile, when the plague reached the Chinese towns of Mukden and Changchun to the south, they had less coordinated responses that "maintained sensitivity to local custom and a sense of autonomy," but which do not appear to have been significantly less effective than the responses in Harbin. ${ }^{10}$ Finally, even further south, the new city of Dairen had been planned by the Russians and later developed by the Japanese and had a comparatively efficient military administration, though the city's approaches to public health were never put to the test given that the plague never fully arrived there. At the same time, however, even as Summers emphasizes the divergent sociomedical responses adopted by different cities in response to the Manchurian plague, he also points out that this outbreak was also the catalyst for the International Plague Conference held in Mukden in April 1911, which was the first international scientific meeting held in China and anticipated the sort of international health-policy coordination that has become more common in the contemporary period.

Coincidentally, it was also in 1910 - the same year the plague struck Manchuriathat the United States officially opened an immigration detention center on Angel Island, off the coast of San Francisco. Angel Island was already a health inspection and quarantine station starting in the early 1890s, but from 1910 to 1940, Angel Island Immigration Station was the primary port of arrival for most Chinese people seeking to visit or immigrate to the United States, and therefore came to symbolize America's treatment of Chinese arrivals in the shadow of the Chinese Exclusion Act of 1882. In addition to having to confirm their identity, immigrants passing through Angel Island

10. Summers, 1054 
were also carefully screened for a variety of infectious diseases, including parasites such as hookworm, whipworm, and roundworm, as well bacterial infections such as cholera, leprosy, or the plague-reflecting the widespread perception during this period that Chinese individuals and Chinese communities were prime repositories of disease. ${ }^{11}$

It is the resulting intersection of concerns with disease and racial difference that is the focus of Nayan Shah's 2002 book Contagious Divides: Epidemics and Race in San Francisco's Chinatown. In his study, Shah examines the intersection of immigration and public health as they relate the city of San Francisco from the late-nineteenth and early-twentieth centuries. In particular, he argues that during this period, popular perceptions of the city's Chinatown and its Chinese residents underwent a crucial transformation, shifting from a late nineteenth-century focus on the threat that Chinatown and its residents posed to the health of the rest of the city to a later attention, as early as the 1930s, to Chinatown's residents as deserving citizens who were entitled to the support of the city's medical establishment. Shah argues that a key factor in this transition from regulation to entitlement was a wave of political activism on the part of university-educated second-generation Chinese immigrants who succeeded in shifting the discursive parameters surrounding the city's Chinese residents and neighborhoods.

Just as the Third Pandemic was the first "new" global health crisis in the twentieth century, SARS similarly marked the first new global health crisis of the twenty-first century. Both epidemics followed a similar geographic trajectory, and just as the Third Pandemic appears to have originated in southwestern China before being transmitted to Hong Kong, the earliest known cases of what would come to be identified as SARS were similarly reported in southern China in late 2002. By early 2003, the virus had reached Hong Kong, from which it then quickly spread to Taipei, Singapore, Hanoi, Toronto, and several other cities around the world. Moreover, just as the Third Pandemic coincided with important developments in biomedical research and public-health policy, the SARS epidemic also occurred at an important inflection point in medical knowledge and public-health policies_-both at global and at national levels.

In her study Infectious Change: Reinventing Chinese Public Health After an Epidemic, for instance, Katherine Mason notes that the SARS outbreak happened to coincide with a major shift in China's public-health system. ${ }^{12}$ In particular, in 2002, on the very eve of the SARS outbreak, China split each of its Soviet-style Anti-Epidemic Stations into two subunits consisting of a Health Inspection Institute, on one hand, and USstyle Centers for Disease Control and Prevention (CDC), on the other. Unlike the original Anti-Epidemic Stations, which focused primarily on public sanitation inspections, the new CDCs concentrated instead on medical research and broad epidemiological

11. Shah, Contagious Divides: Epidemics and Race in San Francisco (Berkeley: University of California Press, 2002).

12. Katherine Mason, Infectious Change: Reinventing Chinese Public Health after an Epidemic (Stanford, CA: Stanford University Press, 2016). 
analysis. Mason argues that one result of this structural transformation is that the medical establishment's attention shifted from "stopping disease in individuals" to "stopping the spread of disease" within society. ${ }^{13}$ This shift, in turn, had important implications not only for the nation's public-health policy but also for the medical establishment's attitudes toward individual patients. At the same time, however, Mason-who spent much of 2008 and 2009 embedded in the CDC of a newly established southern Chinese city referred to pseudonymously as "Tianmai" (though, as Mason observes, "readers familiar with China may have little difficulty identifying the true identity of Tianmai") — notes that it remains possible for highly motivated medical professionals to pursue a strategy of "personal, individualized investment and trust acting as a gateway for good public health stewardship," ${ }^{14}$ as in the case of one highly motivated HIV researcher she came to know who was unusually attentive to the personal challenges faced by his patients and who served as a role model for the other physicians on his team.

Another study published in the aftermath of the SARS crisis is Arthur Kleinman and James Watson's 2006 edited volume SARS in China: Prelude to Pandemic? ${ }^{15}$ Based on a conference held at Harvard in September 2003, SARS in China features papers that use a variety of different disciplinary perspectives to look back at the SARS epidemic. Although SARS brought Hong Kong and other regions in Greater China to a virtual standstill in the late winter and spring of 2003, the outbreak fortunately remained relatively contained and ultimately resulted in less than eight hundred confirmed deaths worldwide. By the mid-summer of 2003, most of the previously affected regions were reporting no new local transmission, and since mid-2004 there have been no known cases of SARS anywhere in the world. However, the fact that the SARS outbreak was ultimately not as dangerous as it could have been does not mean that it should now be ignored, and, as Kleinman and Watson explain in their preface, they hope that the volume will not only offer a better understanding of the SARS outbreak itself but also that it "will be put to practical use — in ways that we cannot anticipate-by people who find themselves in the firing line of the next global epidemic." 16

Written by a combination of historians and anthropologists, each of the preceding four volumes examine infectious disease in a global context but with a focus on regional differences. Although one of the key concerns of each of these studies involves the ramifications of different approaches to public-health policy, an underlying issue that runs through each work involves a set of imbricated assumptions about illness and ethnicity, including the widespread perception in the West and the Global North that infectious

13. Mason, Infectious Change, 16.

14. Mason, 199.

15. Arthur Kleinman and James Watson, SARS in China: Prelude to a Pandemic? (Stanford, CA: Stanford University Press, 2006).

16. Kleinman and Watson, SARS in China, viii. 
diseases are typically brought in from elsewhere, and particularly from the East and Global South. Although this association of the East and the Global South with infectious disease is often linked to a perception that the regions in question are characterized by high poverty levels, densely populated metropolises, and close contact between humans and wildlife, it is also compounded by a set of racist and Orientalist attitudes. When Covid-19 began circulating worldwide, for instance, many international commentators called it as the Wuhan virus, the China virus, and so forth, emphasizing the outbreak's apparent origins in Wuhan's "wet markets" (open-air markets selling fish, meat, and, sometimes, live animals). Although the precise origins of the virus have not been conclusively established, the notion that Wuhan, a major Chinese city with over ten million residents, was some sort of cultural backwater proved oddly compelling for many commentators.

In her 2007 study Contagious: Cultures, Carriers, and the Outbreak Narrative, meanwhile, literary scholar Priscilla Wald focuses precisely on these questions of cultural representations of disease and the assumptions on which they are predicated. ${ }^{17}$ In particular, Wald focuses on what she calls "the outbreak narrative" that emerged in the late twentieth century following the identification of HIV and argues that this narrative became a dominant way of framing the threat of infectious disease in scientific, journalistic, and fictional discourses. In Wald's account, the outbreak narrative possesses a set of distinctive characteristics, including a focus on a "patient zero," an initial outbreak in a putatively remote location (remote, at least, from the perspective of the Global North), a subsequent process of transregional dissemination via carriers and "superspreaders," ultimately concluding with the North's successful containment and even eradication of the disease. For instance, Wald opens Contagious with an example of how the outbreak narrative shaped accounts of and responses to the 2002-2003 SARS outbreak, and particularly how the syndrome caused by this "brand-new coronavirus" was quickly linked to the category of "emerging infections" (a term coined only two decades earlier) and sparked fears that this might mark the long-expected arrival of the "coming plague." 18 These observations apply equally well to scientific and popular coverage of the Covid-19 crisis, particularly in the media's emphasis on the outbreak's origins in Wuhan's wet markets, the repeated comparisons to devastating pandemics such as the 1918 Spanish influenza, and the widespread confidence that an effective vaccine will soon be widely available.

Wald argues that that the growing influence of this narrative has important implications for our understanding not only of infectious disease itself but also of the underlying processes of globalization that facilitate their emergence and transnational

17. Priscilla Wald, Contagious: Cultures, Carriers, and the Outbreak Narrative (Durham, NC: Duke University Press, 2008). 18. Wald, Contagious, 270. 
dissemination. In particular, she observes that the outbreak narrative fosters a perception of the Global North continually threatened by the infectious threat posed by the Global South. She proposes, accordingly, that it would be productive to rethink the stories that we tell about disease and globalization and to replace the existing pandemic narrative with alternative narratives (new "stories") that instead "tell the story of disease emergence and human connection in the language of social justice rather than of susceptibility." In particular, she suggests that these new narratives could underscore the degree to which disease emergence "is an urgent problem in the North not only, or even primarily, because disease may spread from the South to the North, but because of the role of the North in perpetuating the conditions of thirdworldification worldwide." 19 In this way, these alternate discourses could help improve not only how we discuss infectious disease itself but also how we understand and address the underlying causal factors (and their attendant sociopolitical implications) that contribute to specific disease outbreaks.

19. Wald, 270. 